Original Research Paper

\title{
Assessing the Environmental and Socio-Economic Risk Factors of Climate Vulnerability in Low-Income Settlements of Kitwe City in Zambia
}

\author{
${ }^{1}$ George Kasali, ${ }^{1}$ Julius Kanyembo, ${ }^{2}$ Mapenzi Phiri and ${ }^{3}$ Mainza Sibajene \\ ${ }^{I}$ The Copperbelt University, P.O. Box 21692, Kitwe, Zambia \\ ${ }^{2}$ People's Process on Housing and Poverty in Zambia, P.O. Box 36202, Lusaka, Zambia \\ ${ }^{3}$ Kitwe City Council, P.O. Box 20070, Kitwe, Zambia
}

Article history

Received: 20-12-2016

Revised: 06-02-2017

Accepted: 16-03-2017

Corresponding Author:

George Kasali

The Copperbelt University,

P.O. Box 21692, Kitwe,

Zambia

Tell: +260977476610

Fax: +260-212-228214

Email: kasali_george@yahoo.com

\begin{abstract}
Recent findings of the Intergovernmental Panel on Climate Change have clearly shown that climate change represents an urgent and irreversible threat to human societies and the planet and especially to the social and economic development of Africa.Therefore, the purpose of this study was to determine and identify the risk factors associated with climate vulnerability in selected slum settlements of Kitwe city in Zambia. The methodological approach utilized household questionnaire surveys of one middle-income (Kwacha East) and four low-income (Ipusukilo, Mulenga, Chipata and Kawama) settlements to determine the Climate Vulnerability Index (CVI) based on exposure, sensitivity and adaptive capacity of the settlements. The results show that the elements of exposure in Kitwe are hot temperatures, heavy rain falls, flooding, gusty winds and occasional colder temperatures. Ipusukilo and Chipata have the highest CVIs and overall, the CVI for the middle-income settlement is almost five times lower than the average CVI for all the four low-income settlements. This relatively heightened sensitivity to climate-induced shocks is conditioned by very low levels of adaptive capacity within the low-income settlements. However, the social capital dimension of adaptive capacity is found to be very low across all the five settlements. Therefore, empirically, the main constraint to climate resilience is the low level of organizational capacity to mobilize both internal and external resources for technological capacity-building, human resource development and wealth-creation.
\end{abstract}

Keywords: Vulnerability, Climate Variability, Livelihoods, Urban, Zambia

\section{Introduction}

The findings of the Intergovernmental Panel on Climate Change (IPCC) have indicated that global surface temperature change for the end of the 21 st century is likely to exceed $1.5^{\circ} \mathrm{C}$ if there is no deviation from current emission trends. Consequently, the IPCC has projected increases in the frequency, intensity and/or amount of heavy precipitation, heat waves and droughts in some regions of the world by the 21 st century and beyond (IPCC, 2013).

African countries are characterized by endemic poverty, weak governance and institutional systems, poor infrastructure and technology and ecosystem degradation. These in turn have increased the continent's vulnerability to climate extremes and climate change (IPCC, 2007), while exacerbating existing developmental challenges.

Zambia with a population of 13.5 million persons has, since 2000, experienced nearly annual episodes of droughts and floods, with the $2004 / 05$ drought affecting over $12 \%$ of the population. On the other hand, the 2006/07 floods affected a total of 1,443,583 persons, destroying food/cash crops, settlements, latrines, water wells, schools, clinics, bridges, roads and other infrastructure. The health impacts included outbreaks of cholera and plague (ZVAC, 2008). Over the past three decades, floods and droughts have already financially cost Zambia an estimated US\$13.8 billion or a loss of economic growth equivalent to $0.4 \%$ annually (MFNP, 2011). 
This study focused on the climate vulnerability of slum (low-income) settlements where pre-disposing factors, such as poor housing, drainage, water and sanitation infrastructure predominantly exist (WHO, 2007). Ribot (2009) has also noted that the damages and losses associated with climate extremes are shaped by the social, political and economic vulnerabilities of people and societies on the ground. Accordingly, this study examines the environmental, social and economic drivers of climate vulnerability. Environmental dimensions reflect habitat-related living conditions within urban space, such as access to water, sanitation, drainage and waste collection services. The social aspects relate to issues of age, literacy, health, housing, governance and social relations within urban settlements. The economic factors are intended to capture aspects of livelihood strategies which enable populations to access income and food.This study also adopted the notion that the adaptation deficit or vulnerability to current climate variability is a robust proxy of future vulnerability to climate change (Mearns and Norton, 2009).

Zambia, being a party to the United Nations Framework Convention on Climate Change, is required to develop and implement climate change action plans, which should cater for both urban and rural areas. However, to date, there is neither a single city nor town in Zambia that has so far managed to develop a city/town climate change action plan.

The first logical step in developing climate change action plans is to conduct a climate vulnerability assessment of the given locality so as to generate data and information for policy development and formulation of specific interventions aimed at reducing climate vulnerability. The objectives of this study were thus to identify, determine and compare the risk factors associated with climate vulnerability in five urban settlements of Kitwe city in Zambia and formulate context-specific strategies which should serve as a basis for future development of action plans for reducing climate vulnerability in Kitwe city.

\section{Methodology}

The methodological approach adopted and adapted for this study was that of Hahn et al. (2009), which is based on the principles of the Sustainable Livelihoods (SL) framework, whereby the current household livelihood conditions serve as proxies or indicators of vulnerability to the impacts of climate variability/change. The advantage of this climate vulnerability assessment approach is that it does not rely on climate projections, which are quite rare and usually not location-specific for most parts of Africa, but uses current living conditions to quantify the resilience of livelihood systems in the face of the changing climate.

\section{Description of the Study Area}

Kitwe was established as a copper mining centre in 1936 and it achieved city status in May 1967.

Geographically, the total land area of Kitwe is about $32 \mathrm{~km}$ wide and $64 \mathrm{~km}$ long and is located between latitudes $12^{\circ}$ and $13^{\circ}$ south and longitudes $27^{\circ}$ and $29^{\circ}$ east. The mean annual rainfall for Kitwe city is around $1226 \mathrm{~mm}$ and due to its proximity to the equator, the city does receive at times very heavy rainfall. The city is drained by Kafue River on the eastern side, while Mindolo, Kitwe, Uchi and Wusakile streams cut across the city from west to the east into Kafue River (Fig. 1). Kafue River serves as the main water supply source for the entire city.

Kitwe's main economic activity is mining copper and cobalt and in the mid-60 s the thriving mining industry provided the backbone for the emergence of the manufacturing and service sector industries in Kitwe. However, when the mines were privatised from the mid-90s onwards, the city began to witness massive job losses, infrastructure decay, urban destitution and squalid housing conditions. Small-scale trading, since the liberalisation of the economy, has become a significant provider of informal employment in the city (UN HABITAT, 2009).

Based on the 2010 census, the present population of Kitwe city stands at 522,092 comprising 260,216 and 261,876 males and females, respectively (CSO, 2011). The current annual population growth rate is $3.3 \%$. The city has about 24 formal settlements and about 19 informal settlements (slums) with few or no basic services. Only seven (7) of these slums have so far been approved by Kitwe City Council for upgrading. The current pilot study on climate vulnerability assessment in Kitwe targeted four informal or low-income settlements (Mulenga, Chipata, Ipusukilo and Kawama) and one formal (middle-income) settlement (Fig. 1).

\section{Research Methods}

The climate vulnerability or climate resilience levels of the settlements in Kitwe were assessed by constructing the Livelihood Vulnerability Index (LVI) and the corresponding Climate Vulnerability Index (CVI) for each settlement. The CVI is derived from the LVI. These indices enable the comparative assessment of the climate vulnerability patterns amongst the respective settlements based on current living conditions.

\section{Sampling}

Five settlements were selected for this study and the selection criteria included the following characteristics:

- Settlements where People's Process on Housing and Poverty in Zambia (a non-governmental 
organisation) has been either conducting its enumeration (profiling) activities or constructing houses for the homeless

- Settlements which are under consideration by Kitwe City Council (KCC) for upgrading or relocation

- Settlements with a history of climate-related disasters

Using the above criteria, four squatter/informal (slum) or low-income settlements were selected, namely, Kawama, Chipata, Mulenga and Ipusukilo. Kwacha east was included as the fifth settlement for comparison purposes since it was a middle-income planned settlement.

The sample size for the household questionnaire survey was computed based on the formula in the WHO (2005) methodology which is used to determine a statistically viable sample size in communities where the actual prevalence levels of indicator parameters are unknown. Having used a sample size calculation (WHO, 2005 ) at the $95 \%$ confidence interval, $5 \%$ precision, $50 \%$ prevalence and a design effect of 2 to account for cluster sampling, 100 households were surveyed in each of the five settlements of Kawama, Chipata, Mulenga, Ipusukilo and Kwacha East.

\section{Data Collection}

Data collection comprised of household questionnaire surveys in the five selected settlements of Kitwe. Data collection was conducted by field staff from Kitwe City Council, Peoples Process on Housing and Poverty in Zambia (PPHPZ), the Zambia Youth Federation and the Zambia Homeless and Poor Peoples Federation (ZHPPF). These interviewers were all speakers of the local language (Bemba) and English to enable them administer the questionnaire in both languages. The questionnaire covered sections on indicators of livelihood domains, namely, Sociodemographics, Livelihood strategies, Health, Social capital, Food, Water, Sanitation/Drainage, Housing, Natural hazards and Climate variability.

Climate data comprising of daily temperature and rainfall records were also collected from Mopani Copper Mines Limited in Kitwe. The temperature data covered a period from 2003 to 2011, while rainfall data were from 1929 to 2007 . Data were also collected from gray literature (internet, radio, television and newspapers) on the occurrence of flooding, epidemics and other climate-related disasters in Kitwe.

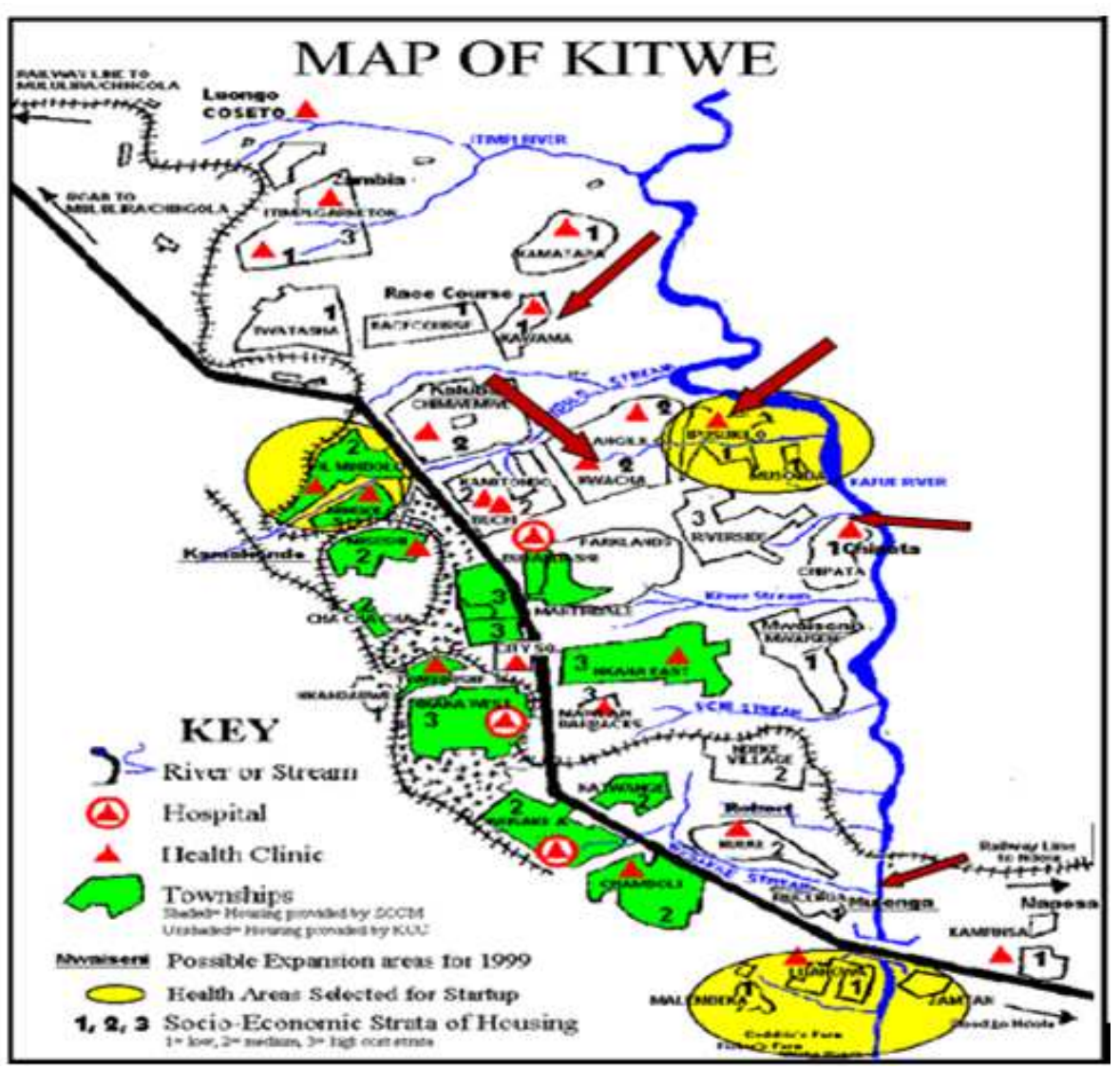

Fig. 1. Map of Kitwe with arrows showing the settlements surveyed under this study 


\section{Data Analysis}

The data analysis procedures adopted for this study were those devised and developed by Hahn et al. (2009). However, these authors applied this methodology in a rural setting and compared the climate resilience of two villages. Consequently, we had to adapt the methodology to work for urban settlements by including additional domains, such as sanitation, drainage and housing infrastructure, which are critical determinants of climate vulnerability in urban areas. In essence, this addition of indicators did not change the fundamental steps for calculating the LVI and CVI indices as elaborated by Hahn et al. (2009). The actual data analysis procedures used in this study are presented below.

\section{Calculating the Livelihood Vulnerability Indices (LVI)}

The main steps of the LVI method as developed and applied by Hahn et al. (2009) are briefly described below.

Firstly, the household questionnaire survey provided responses for indicators pertaining to the following livelihood domains: Socio-Demographic Profile, Livelihood Strategies, Social Capital/Networks, Health, Food, Water, Sanitation/Drainage, Housing and Natural Disasters and Climate Variability. The indicators used for the various domains were not measured in the same units and hence it was necessary to standardize each indicator as an index. Accordingly, a balanced weighted average approach was applied, where each indicator was assumed to contribute equally to the overall index even though each domain was comprised of a different number of indicators. To standardize each indicator as an index, the equation below was used:

$$
\text { index }_{s_{s}}=\frac{S_{s}-s_{\min }}{s_{\max }-s_{\min }}
$$

where, $S_{s}$ is the original indicator value for settlements and $S_{\min }$ and $S_{\max }$ are the minimum and maximum values, respectively, for each indicator determined using data from the five settlements.
Secondly, after each indicator was standardized, the index scores for each livelihood domain were calculated by summing the indicator indices and then dividing by the number of indicators in each domain.

Thirdly, the Livelihood Vulnerability Indices (LVIs) for each settlement were calculated by summing the weighted average values of the nine livelihood domains and dividing by the sum of the number of indicators in each of the nine domains. The LVIs scaled from 0 (least vulnerable) to 1 (most vulnerable). Details of the equations used can be found in Hahn et al. (2009). The LVI results were then used to determine the climate vulnerability indices for each settlement as presented in the next section.

\section{Calculating the LVI-IPCC or Climate Vulnerability Indices (CVI)}

Hahn et al. (2009) have termed the Climate Vulnerability Index (CVI) as the LVI-IPCC index because it incorporates the IPCC vulnerability definition by clustering the livelihood domains under the three components (exposure, sensitivity and adaptive capacity) of climate vulnerability, as shown below.

Table 1 shows the organization of the nine livelihood domains in the CVI framework where the nine livelihood domains are categorised into the three elements of climate vulnerability.

The same indicators used for calculating the LVI above were used to calculate the CVI except that rather than merge the domains in one step as when calculating the LVI, they were first combined according to the categorization scheme in Table 1 above. However, in the calculation of the adaptive capacity index score for CVI, the inverse of the domain indicator was used. For example, if the 'number of informally-employed households' were used as the indicator in the calculation of LVI, then for CVI purposes, the inverse indicator of the 'number of formally-employed households' was used to calculate adaptive capacity score. This was intended to account for the fact that adaptive capacity is inversely correlated with climate vulnerability. The equations used for calculating the exposure, sensitivity and adaptive capacity indices of the settlements can be found in Hahn et al. (2009).

Table 1. Categorisation of the nine domains into climate vulnerability elements of exposure, sensitivity and adaptive capacity

\begin{tabular}{ll}
\hline Climate vulnerability elements/categories & Livelihood domains \\
\hline Exposure & Natural disasters and climate variability \\
Adaptive capacity & Socio-demographic profile \\
& Livelihood strategies \\
Sensitivity & Social capital/networks \\
& Health \\
& Food \\
& Water \\
& Sanitation/Drainage \\
\hline
\end{tabular}


Once exposure, sensitivity and adaptive capacity indices were calculated, the three elements were combined to calculate the CVI by multiplying the exposure and sensitivity scores and then dividing by the adaptive capacity score. The actual equation employed can be found in Sharma et al. (2010). The CVI scaled from 0 (least vulnerable) to 1 (most vulnerable).

Calculation of the number of rainy days was based on the definition of a rainy day as a day with non-zero value of precipitation during the rainy season. Annual rainfall intensity was calculated as total seasonal rainfall divided by the number of rainy days in the season. This value actually works out to be the mean daily rainfall intensity (mm/day) of a given season.

The calculations involving both primary and secondary data, which were collected for this study, were done using the SPSS and Excel analytical packages.

\section{Results and Discussion}

The primary data from the questionnaires and the secondary data used in this study provided empirical information to enable the characterisation of the five settlements in Kitwe with regard to local climate trends, risk factors of climate vulnerability, impacts of climaterelated hazards on livelihoods and the existent coping practices in the face of climate-induced shocks. These and other dimensions of climate vulnerability are presented and discussed below.

\section{Historical Climate Trends}

Climate change is expected to place additional complexity on urban household livelihood processes and systems by either degenerating or enhancing the quality of living conditions for the affected communities. It is, therefore, cardinal and important to determine and understand the views, perceptions and experiences of people concerning patterns and trends of climate events in a particular locality. This helps to contextualise climatic events within the livelihood peculiarities of the targeted communities.

The responses from the five settlements are presented in Fig. 2, where it is indicative that the respondents identified hot temperatures, heavier rainfalls, strong winds and cold temperatures as some of the meteorological hazards of concern in Kitwe.

An attempt was made to complement community perceptions and observations with analyses of actual measured temperature and rainfall data for Kitwe.

The obtained daily temperature data for this study were, unfortunately, for a short period of only nine years (2003-2011). The data were, thus, just summarized to detect mean average, minimum (Min) and maximum (Max) seasonal temperature conditions for Kitwe over the nine year period (Table 2). It is evident that for all the three seasons, the mean seasonal temperature values are almost within the human thermal comfort zone (19$29^{\circ} \mathrm{C}$ ) for sedentary and strenuous physical activities in Zambia (Malama and Sharples, 1997). However, the high-end side of all seasonal ranges is above $30^{\circ} \mathrm{C}$. Ambient temperatures above $32^{\circ} \mathrm{C}$ have been shown (Barnett et al., 2013) to exacerbate the environmental heat load, resulting in heat stress conditions for the exposed population.

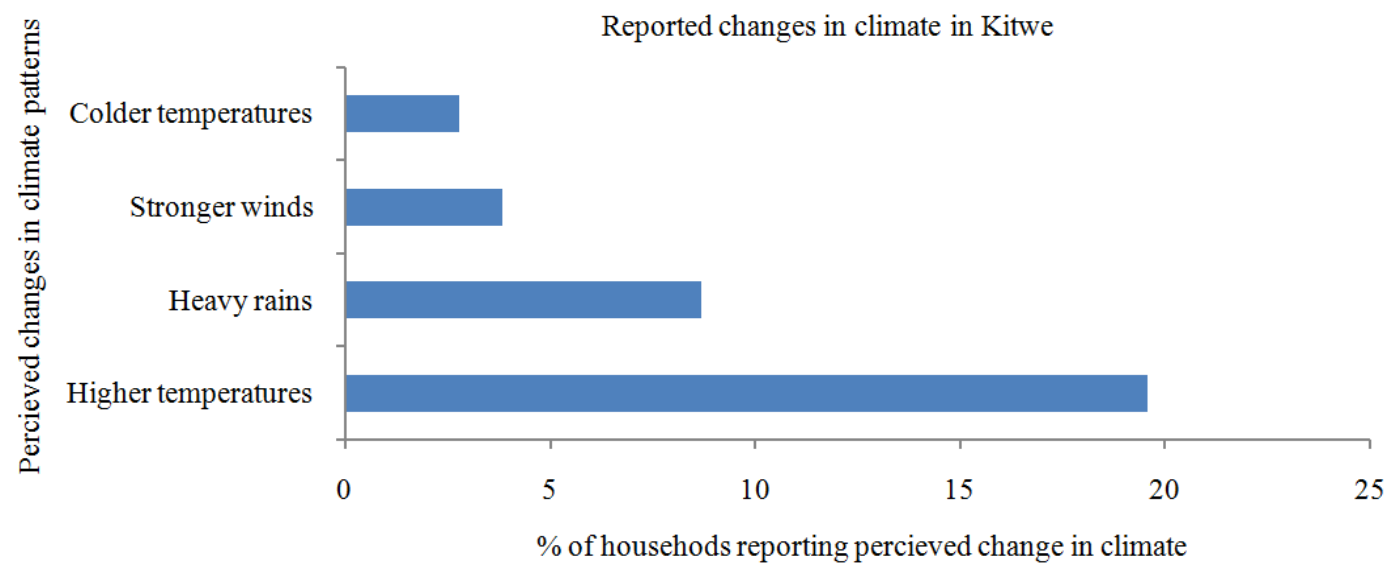

Fig. 2. Reported perceived changes in climate of Kitwe for the past 20 years

Table 2. Mean seasonal temperature values for Kitwe (2003-2011)

\begin{tabular}{lllll}
\hline Season of the year & $\begin{array}{l}\text { Mean seasonal } \\
\text { temp }\left({ }^{\circ} \mathrm{C}\right)\end{array}$ & $\begin{array}{l}\text { Seasonal mean } \\
\text { min temp }\left({ }^{\circ} \mathrm{C}\right)\end{array}$ & $\begin{array}{l}\text { Seasonal mean } \\
\max \text { temp }\left({ }^{\circ} \mathrm{C}\right)\end{array}$ & $\begin{array}{l}\text { Seasonal temp } \\
\text { range }\left({ }^{\circ} \mathrm{C}\right)\end{array}$ \\
\hline Cold-dry season (May to July) & 18.7 & 13.5 & 28.0 & $8.3-31.5$ \\
Hot-dry season (August to October) & 23.4 & 17.8 & 31.0 & $10.3-37.3$ \\
Hot-wet season (November to April) & 23.5 & 20.1 & 30.0 & $14.6-36.8$ \\
\hline
\end{tabular}


These hot-temperature regimes were associated with the hot-dry and hot-wet seasons (Table 2) in Kitwe over the nine-year period and the perceptions of increasing temperatures by residents of Kitwe (Fig. 2) could be a reflection of these types of temperature regimes. However, the perceptions of rising temperatures are actually in conformity with climatic analyses which have shown that the mean annual temperature in Zambia has increased by $1.3^{\circ} \mathrm{C}$ since 1960 , at an average rate of $0.29^{\circ} \mathrm{C}$ per decade (MTENR, 2010). In October 2016, the Zambia Meteorological Deaprtment - ZMD (2016) reported the unusual maximum temperatures of 40 and $41^{\circ} \mathrm{C}$ in some parts of Zambia.

The perception of temperatures getting colder (intense cold) by the respondents is difficult to associate with any scientific evidence. However, suffice to state that it was ubiquitously observed in Kitwe and surrounding towns that during the 2012 cold season (May-July), banana and cassava plants unusually suffered chilling injury with their leaves turning yellow. Bananas have been shown to stop growing at temperatures below $9^{\circ} \mathrm{C}$ (Turner, 2003). In some parts of Zambia, temperatures of below $4^{\circ} \mathrm{C}$ were recorded during July 2015 (ZMD, 2015).

The residents of Kitwe also implicated strong winds in the arsenal of climatic elements that were on the increase in the area (Fig. 2). There are as yet no studies on the evolution of trends in wind speeds over Kitwe. In 2012 these gusty winds or hailstorms uprooted trees and blew off roofs of even professionally-constructed buildings at the Copperbelt University and other parts of Kitwe.

Analysis of rainfall data for Kitwe for the period of 1929-2007 revealed that the mean annual rainfall over the analysis period was $1303.3 \mathrm{~mm}$. The maximum rainfall recorded was $2004 \mathrm{~mm}$ which occurred during the 1951/52 rainfall season, while the minimum rainfall so far recorded in Kitwe was $789.9 \mathrm{~mm}$ during the $1957 / 58$ season. Overall, the daily rainfall intensity has increased over the years (Fig. 3).

The mean daily rainfall intensity actually increased from 11.1 during the $1929 / 30$ rainy season to 20.6 $\mathrm{mm}$ /day in the $2006 / 07$ season. This finding, in a way, is in conformity with the perceptions of Kitwe residents that rainfall events have been getting heavier (Fig. 2). Actually, according to climate models for Zambia (MTENR, 2010), the proportion of total rainfall that falls in heavy events is projected to increase annually, mainly in December, January and February.

\section{Risk Factors for Urban Climate Vulnerability}

According to the IPCC (2012), the severity of the impacts of climate events depends strongly on the level of vulnerability and exposure to these events in particular localities. Therefore, understanding the environmental and socio-economic dimensions of vulnerability and exposure is a prerequisite for determining how weather and climate events contribute to the occurrence of disasters and for designing and implementing effective adaptation and disaster risk management strategies. In this study, the values of the various indicators of vulnerability were indexed to enable ranking of the five settlements and the results are presented in the sections below. However, given that vulnerability is location-specific, the ranking should be interpreted as being valid within the study sample only.

\section{Socio-Demographic Profiles}

One of the determinants of climate vulnerability examined was the socio-demographic profiles of the households in the surveyed settlements of Kitwe. The indicators used for quantifying the levels of these profiles are presented in Table 3.

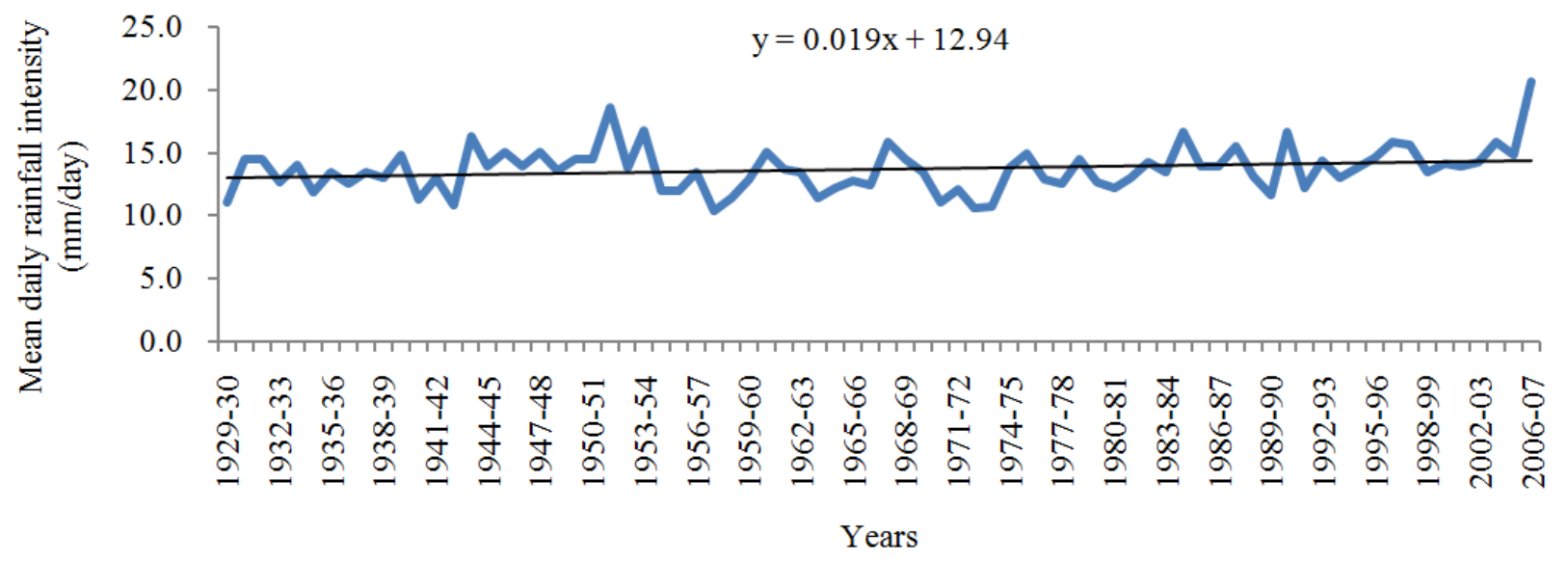

Fig. 3. Variability in mean daily rainfall intensity for Kitwe (1929-2007) 
Table 3. Standardized indicator values of livelihood domains of the five settlements in Kitwe city

\begin{tabular}{|c|c|c|c|c|c|}
\hline \multirow[b]{2}{*}{ Indicators and respective livelihood domains } & \multicolumn{5}{|c|}{ Indicator and Domain indices of Settlements } \\
\hline & Chipata & Ipusukilo & Kawama & Mulenga & Kwacha east \\
\hline Households (hhs) with dependant orphans (\% of hhs with dependant orphans) & 0.253 & 0.320 & 0.450 & 0.184 & 0.410 \\
\hline Education level (\% of hhs whose heads have primary education only) & 0.434 & 0.480 & 0.530 & 0.408 & 0.160 \\
\hline Age ( $\%$ of hhs with heads of hhs aged over 65 years) & 0.202 & 0.210 & 0.020 & 0.092 & 0.100 \\
\hline Socio-demographic profile indices & 0.296 & 0.337 & 0.333 & 0.228 & 0.223 \\
\hline$\%$ of hhs in informal employment & 0.465 & 0.630 & 0.640 & 0.714 & 0.420 \\
\hline$\%$ of hhs with monthly incomes of USD $10-80$ & 0.485 & 0.670 & 0.530 & 0.796 & 0.230 \\
\hline$\%$ of hhs spending USD8-10/month on staple food (maize-meal) & 0.051 & 0.290 & 0.130 & 0.296 & 0.230 \\
\hline$\%$ of hhs spending nothing on electricity (do not have access to electricity) & 0.96 & 0.915 & 0.885 & 0.671 & 0.000 \\
\hline$\%$ of hhs reporting "none" assets to sell if current source of income got lost & 0.667 & 0.690 & 0.710 & 0.561 & 0.160 \\
\hline Livelihood Strategies indices & 0.526 & 0.639 & 0.579 & 0.608 & 0.208 \\
\hline Is anybody in your family chronically ill? (\% of hhs reporting “yes") & 0.323 & 0.200 & 0.130 & 0.449 & 0.190 \\
\hline $\begin{array}{l}\text { Does anybody in the household suffer from chronic respiratory diseases? } \\
\text { (\% of hhs reporting "yes") }\end{array}$ & 0.081 & 0.070 & 0.030 & 0.143 & 0.020 \\
\hline How many mosquito nets do you have in the household? (\% of hh reporting 'none') & 0.354 & 0.606 & 0.290 & 0.327 & 0.250 \\
\hline $\begin{array}{l}\text { Which is the most common disease that usually afflicts the household? (\% of } \\
\text { hhs reporting "diarrhoeal diseases') }\end{array}$ & 0.203 & 0.220 & 0.040 & 0.102 & 0.120 \\
\hline $\begin{array}{l}\text { How long does it take you to walk to a health centre? ( } \% \text { of hhs reporting } \\
\text { ' } 31 \text { minutes and above') }\end{array}$ & 0.717 & 0.040 & 0.420 & 0.367 & 0.200 \\
\hline Health indices & 0.336 & 0.227 & 0.182 & 0.278 & 0.156 \\
\hline Are there drainages in the community? (\% of hh reporting 'no') & 0.990 & 0.740 & 0.970 & 0.684 & 0.740 \\
\hline What type of toilet do you use? (\% of hh reporting 'pit latrines') & 1.000 & 0.970 & 0.990 & 0.980 & 0.376 \\
\hline Sanitation/drainage indices & 0.995 & 0.855 & 0.980 & 0.832 & 0.558 \\
\hline$\%$ of hhs sourcing drinking water from shallow wells. & 0.909 & 0.650 & 0.850 & 0.541 & 0.000 \\
\hline$\%$ of hhs sourcing water for cooking from shallow wells. & 0.919 & 0.610 & 0.860 & 0.551 & 0.000 \\
\hline$\%$ of hhs that have heard about water conflicts in their community in the past year. & 0.192 & 0.160 & 0.580 & 0.490 & 0.130 \\
\hline$\%$ of hhs that have observed pollution of their water sources. & 0.040 & 0.071 & 0.020 & 0.143 & 0.040 \\
\hline Water indices & 0.515 & 0.373 & 0.578 & 0.431 & 0.043 \\
\hline$\%$ of hhs whose houses had walls constructed of mud/clay bricks. & 0.879 & 0.640 & 0.590 & 0.480 & 0.000 \\
\hline$\%$ of hhs with house floors made from mud/clay soils. & 0.737 & 0.550 & 0.630 & 0.357 & 0.000 \\
\hline$\%$ of hhs with houses roofed with iron sheets. & 0.869 & 0.720 & 0.860 & 0.949 & 0.160 \\
\hline Housing indices & 0.828 & 0.637 & 0.693 & 0.595 & 0.053 \\
\hline$\%$ of hhs that grow their own food & 0.202 & 0.220 & 0.290 & 0.48 & 0.410 \\
\hline$\%$ of hhs that normally eat 'one meal' per day & 0.222 & 0.240 & 0.020 & 0.112 & 0.020 \\
\hline$\%$ of hhs that eat only one meal per day during the rainy season & 0.323 & 0.460 & 0.390 & 0.429 & 0.230 \\
\hline$\%$ of hhs that do not save any money for use during stressful times & 0.949 & 0.820 & 0.650 & 0.622 & 0.600 \\
\hline Food indices & 0.424 & 0.435 & 0.338 & 0.411 & 0.315 \\
\hline $\begin{array}{l}\% \text { of hhs reporting not having helped neighbours, friends nor relatives } \\
\text { in the past one month. }\end{array}$ & 0.949 & 0.530 & 0.700 & 0.531 & 0.290 \\
\hline $\begin{array}{l}\% \text { of hhs reporting not having lent any money to neighbours, friends } \\
\text { nor relatives in the past one month. }\end{array}$ & 0.939 & 0.690 & 0.850 & 0.663 & 0.670 \\
\hline $\begin{array}{l}\% \text { of hhs reporting not having received any help from civic leaders in } \\
\text { the past twelve months. }\end{array}$ & 0.990 & 0.770 & 0.970 & 0.898 & 0.840 \\
\hline$\%$ of hhs that have never received any community-based training on income generation. & 0.980 & 0.770 & 0.910 & 0.878 & 0.570 \\
\hline$\%$ of hhs which never receive remittances. & 0.980 & 0.570 & 0.760 & 0.673 & 0.260 \\
\hline$\%$ of hhs that have never heard about climate change. & 0.687 & 0.790 & 0.940 & 0.531 & 0.390 \\
\hline Social capital indices & 0.921 & 0.687 & 0.855 & 0.696 & 0.503 \\
\hline Has the household been affected by floods ( $\%$ of hh reporting 'yes'). & 0.192 & 0.190 & 0.000 & 0.153 & 0.020 \\
\hline Has the household been affected by strong winds ( $\%$ of hh reporting 'yes'). & 0.071 & 0.050 & 0.030 & 0.061 & 0.020 \\
\hline $\begin{array}{l}\text { Mean standard deviation of monthly average of average maximum daily } \\
\text { temperature (years: 2003-2011). }\end{array}$ & 0.414 & 0.414 & 0.414 & 0.414 & 0.414 \\
\hline $\begin{array}{l}\text { Mean standard deviation of monthly average of average minimum daily } \\
\text { temperature (years: 2003-2011). }\end{array}$ & 0.516 & 0.516 & 0.516 & 0.516 & 0.516 \\
\hline Mean standard deviation of monthly average precipitation (years: 1930-2007). & 0.576 & 0.576 & 0.576 & 0.576 & 0.576 \\
\hline Percent of households that did not receive a warning about the pending natural disasters. & 1.000 & 1.000 & 1.000 & 1.000 & 1.000 \\
\hline Percent of households with an injury or death as a result of recent natural disasters. & 0.000 & 0.020 & 0.000 & 0.061 & 0.060 \\
\hline Natural hazards and climate variability indices & 0.396 & 0.395 & 0.362 & 0.397 & 0.372 \\
\hline
\end{tabular}
NB: hhs =households

The socio-demographic profile indices (Table 3) of the settlements indicate that the most vulnerable settlements were Ipusukilo and Kawama. Ipusukilo had the highest number of households whose heads were aged above 65 years, while Kawama recorded the highest percentage of households whose heads had primary education only and had dependant orphans.

In Kitwe like the rest of Africa, elderly households typically lack productive employment and regular income and are usually widowed and malnourished- 
factors which make them dependent on others and thus more vulnerable to climate-related shocks. Excess deaths due to extreme heat were also observed among populations aged 65 years onwards (Vaneckova et al., 2010) with the risk continuing to rise with advancing age.

The link between low education and climate vulnerability is the finding that groups with loweducation status usually have limited resources and hence live in neighborhoods with greater exposure to floods and heat stress (Harlan et al., 2006).

The issue of orphans is quite pertinent in the context of Kitwe, especially with the emergence of the HIV/AIDS pandemic in this country. Kitwe's HIV/AIDS prevalence rate of $23.5 \%$ is much higher than the national rate of about $14 \%$ (KCC, 2012). The pandemic has wiped out lives of populations in their reproductive age range of 15-49 years and spawning thousands of orphans in the process. Kitwe has been so ravaged by the pandemic to the extent that the city's annual population growth rate dropped from $4.4 \%$ in the $70 \mathrm{~s}$ before the pandemic to a mere $0.8 \%$ in the $90 \mathrm{~s}$ at the peak of the pandemic and before the advent of free anti-retroviral therapy in this country. Orphans are generally regarded as 'expendable' children and in times of household crises and hardships, they are the first to be turned into street children.

Moreover, the middle-income settlement of Kwacha East had also a high score of orphan-rearing households, indicating that the issue of orphans is a cross-cutting societal challenge in Zambia. In this respect, the most appropriate interventions would be measures aimed at HIV/AIDS prevention and life-prolonging treatment.

\section{Livelihood Strategies}

In the context of the livelihood strategies indices, Ipusukilo and Mulenga exhibited the highest levels of vulnerability due to comparatively high levels of informal employment, low monthly incomes, inadequate food expenditure and high percentages of households without assets and access to electricity (Table 3 ).

Informal employment was found to be widespread in the informal (Chipata, Ipusukilo, Kawama and Mulenga) and formal (Kwacha East) settlements. It was, however, more concentrated in slum settlements with Mulenga recording $71 \%$ of households in informal employment. According to the World Bank (2013), formal employment in 2010 stood at $13 \%$ of total employment in Zambia. Informal jobs are performed in streets, homes, dilapidated markets and in places that are highly vulnerable not only to extremes of temperature and rainfall but also to average climate variability in the country.

The monthly incomes of the majority of households in slum settlements were within the 1-2 US\$ income bracket per day. These are very low incomes and are indicative of households living in extreme poverty. For slum settlements of Ipusukilo, Kawama and Mulenga, over $50 \%$ of the households were living under extreme poverty conditions, with Mulenga actually recording $80 \%$ income-poor households. Income poverty of this magnitude is likely to weaken the capacity of households to climate-proof their livelihoods and to recover from climate-induced losses and damages.

The indicator of percentage of households spending USD8-10/month on staple food was used to gauge the number of households whose incomes were insufficient to provide a decent meal for the family. The urban basic needs basket expenditure per month for the staple food of maize meal was USD16.0 for a family of five in 2015 (JCTR, 2016). Therefore, households in this expenditure bracket are likely to plunge into destitution under climate-induced food price hikes.

The majority of households (67-96\%) in informal settlements had no access to electricity. Conversely, slum dwellers depend on fuelwood (firewood and charcoal) for cooking and kerosene for lighting, thus diminishing the carbon sequestration potential of Zambian forests through deforestation and concurrently generating indoor air pollution. Moreover, charcoal prices perennially undergo hikes due to reduced supply in the rainy season as most charcoal production areas become inaccessible when rains flood the muddy routes and/or damage the bridges.

Household assets serve as livelihood buffers to fall back on when a household is faced with a crisis, such as a house collapsing due to harsh weather. Lack of assets is also an indicator that households are subjected to hand-tomouth living conditions in these slums, with Mulenga ( $71 \%$ of households) being the most vulnerable.

The livelihood strategies index for the middleincome settlement of Kwacha East (0.208) was three times lower than that of Ipusukilo (0.639) slum, emphasising the pervasive levels of extreme poverty that exist in slums of Kitwe. In fact, Kitwe City Council Strategic Plan for 2012-2016 (KCC, 2012) has highlighted the issue of high levels of unemployment as one of the priority problems for the city. Accordingly it is imperative that slums in Kitwe are provided access to climate compatible development opportunities which can simultaneously improve the economic prospects of poorer households through creating jobs and enhancing livelihoods, while forging community development and climate goals.

\section{Health}

The health indices show that Chipata was the most vulnerable, followed by Mulenga and Ipusukilo due to prevalence of chronic illnesses, respiratory diseases, diarrhoea and inadequate access to mosquito nets and health facilities (Table 3). 
Mulenga settlement recorded the highest percentages of households reporting presence of chronically ill family members and presence of family members with chronic respiratory infections. Mulenga settlement is an extension of the former miners' township of Chamboli and is located within walking distance from the Nkana (the other name for Kitwe) Copper Smelter stack that spews sulphur dioxide emissions (locally known as senta) into the air. Additionally, most copper mine workers in Zambia have contracted silicosis (Hayumbu, 2005) which is a debilitating chronic lung disease arising from prolonged exposure to dust particles in the mines. HIV/AIDS and the resurgence of tuberculosis have compounded the prevalence of silicosis in the country. It was, therefore, not unexpected to find relatively higher scores of chronic diseases in Mulenga.

Ipusukilo and Chipata recorded the highest percentage of households experiencing persistent occurrence of diarrhea amongst family members. These two shanty compounds are known for outbreaks of cholera and other diarrheal diseases in Kitwe, especially during the rainy season. Additionally, Chipata does not have a health centre of its own and depends on a clinic located far away in the Riverside high-cost residential area of Kitwe.

A mosquito net is an essential intervention item in the prevention of malaria by households and in this regard, the least protected settlement was Ipusukilo with $61 \%$ of households without mosquito nets. Malaria is a climatesensitive disease and is the number one killer in Zambia, responsible for over 4 million cases and about 33,000 deaths annually (Kamuliwo et al., 2013).

The IPCC (2012) has stated that there is high confidence that climate change will affect disaster risk through indirect impacts on changing disease patterns and general health levels of populations. It is, therefore, necessary to improve public health and health care services in shanty townships of Kitwe for preventing adverse health impacts from climatic events, through surveillance and control activities for infectious diseases, provision of more clinics and enforcement of environmental health regulations.

\section{Sanitation/Drainages}

The overall indices for the sanitation/drainage component are presented in Table 3 where it is shown that Chipata (0.995) was the most vulnerable while Mulenga (0.832) was the least among the slum settlements. Kwacha east scored 0.558 , with the score being highly weighted by inadequate drainage infrastructure in the settlement. In the case of sanitation, almost all the households (97-100\%) in the studied slum settlements depended on pit latrines.

There is concern that climate change will work synergistically with poverty and poor sanitation to increase cholera and other climate-sensitive infectious disease risks (IPCC, 2012). On the other hand, urban drainage systems are recognized as important tools to reduce urban flood risk (UNISDR, 2011). Therefore, it is essential and necessary to strengthen the climate resilience of slums and other residential areas in Kitwe by improving the sanitation standards and coverage of the drainage system.

\section{Water}

Ranking of the five settlements using the water component indicators used in this study revealed that Kawama was the most vulnerable with an index of 0.578 (Table 3). It was followed by Chipata, then Mulenga and Ipusukilo. The middle-income settlement of Kwacha East recorded an index of 0.043 , which was 13 times lower than the index for the low-income settlement of Kawama.

In low-income settlements some residents prefer to use water from shallow wells for cooking and other household chores, while drinking water is obtained at a price from treated sources such as public taps and kiosks. $54-91 \%$ of the households in low-income settlements were found to be using hand-dug shallow wells as sources of drinking water, while 55-92\% were using them for supply of cooking water.

Water conflicts, in the form of quarrels and/or fights, usually arise over crowded water supply sources, such as public taps, kiosks and shared water wells. It is an indicator of water shortages whereby demand exceeds supply. In this study water conflicts were more prevalent in Kawama and Mulenga with 58 and 49\%, respectively, of the households having heard about water conflicts. Water conflicts were also reported in the medium-cost settlement of Kwacha East (13\%) and this was probably due to the chronic water shortages that have persisted in the area for long time. Apart from water shortages, another burden for Kitwe residents is water pollution, usually in the form of visually detectable turbidity of even treated water, especially during the rainy season.

Kitwe City Council (KCC, 2012) noted in its strategic plan that the problem of poor water supply required urgent remedial intervention if communicable diseases were to be prevented in the city, while the IPCC (2012) has highlighted the need for improved and safe water supplies in developing countries, especially for residents of informal settlements.

\section{Housing}

The experience in Kitwe and generally in Zambia is that during events of torrential rains or flooding of residential areas, the houses that normally collapse are those with mud/clay floors and/or with walls of mud/clay bricks. On the other hand, roofs with iron sheets suffer the most damage during events of strong winds and hailstorms. 
Table 3 shows that Chipata had the highest percentage of households, whose houses were made of $\mathrm{mud} /$ clay bricks $(88 \%)$ and mud/clay floors $(74 \%)$. The highest percentage $(95 \%)$ of houses with galvanized iron roofs were found in Mulenga settlement, followed by Chipata, Kawama and Ipusukilo. Iron roofing sheets are the cheapest and thus the most affordable for lowincome households.

In fact, in 2014 over 140 houses collapsed in Ipusukilo and Chipata settlements due to heavy rains. Strengthening local capacity in terms of housing infrastructure is one mechanism shown to improve urban resilience and the adaptive capacity of cities to climate hazards (Pelling, 2003).

\section{Food}

The overall food domain indices (Table 3) for each settlement indicate that Ipusukilo was the most vulnerable to food insecurity, while Kawama was the least vulnerable. However, the index for the middleincome settlement of Kwacha East (0.315) was close to that of the low-income settlement of Kawama (0.338), indicating that the challenges of food insecurity in Kitwe pervade households in both low and middle-income settlements.

In the context of urban Zambia, access to food is largely determined by access to cash and availability of rain-fed maize stocks from own-production. Under current conditions of socially-disarticulated economy when monthly wages hardly last a week, urban Zambians have resorted to farming within their yards or on the outskirts of town to supplement their food sources and/or incomes.

The percentage of households who grew their own food (maize) in the five settlements of Kitwe were relatively higher in the slum of Mulenga (48\%) and the planned settlement of Kwacha East (41\%). However, for the slums of Chipata, Ipusukilo and Kawama, this percentage dropped to almost half (20-29\%).

In Zambia the capacity of households to grow maize is premised on the availability of land and access to commercial seeds and fertilizers. These results presumably reflect the differential constraints faced by households in accessing farming land and agricultural inputs, which are currently heavily subsidized by government for households in cooperatives.

The number of households that were usually eating one meal per day was highest in Ipusukilo (24\%) and lowest in Kawama (2\%) and Kwacha East (2\%). However, during the rainy season, the percentage of households accessing one meal per day increased to over $40 \%$ in Ipusukilo and Mulenga and to more than $30 \%$ in Chipata and Kawama, while Kwacha East recorded $23 \%$. This period (rainy season) coincides with what is referred to in rural areas of Zambia as the hunger season, i.e., the period between November and March, just before the start of maize harvesting in late April, when the rainy season ends. These results might, therefore, indicate the linkage of food security in urban households to food supply chains originating in rural areas or that the rainy season somehow adversely impacts on the income-generating mechanisms of urban households.

The percentage of households which was incapable to save any money ranged from 62 to $95 \%$ for lowincome settlements. The situation was almost similar for Kwacha east with $60 \%$ of such households. When poor households are impacted by disasters, they tend first to expend savings and then, if pressures continue, households can be pushed into destitution or poverty traps, making it impossible for households to rebuild their livelihoods (Ferris, 2011).

The Food and Agricultural Organisation (FAO, 2008) has noted that climate extremes impair food production, storage and delivery systems and that impacts transmitted through an increase in the price of food can be especially challenging for the urban poor in developing countries. Tacoli et al. (2013) have advocated for local governments' support to communitybased/led initiatives to improve food access and safety, so as to reduce food insecurity and contribute to greater resilience of households to the adverse impacts of climate variability and change.

\section{Social Capital}

The social capital domain indices (Table 3) showed Chipata to be the most vulnerable, followed by Kawama, Mulenga, Ipusukilo and Kwacha East, in decreasing order of vulnerability.

Over $50 \%$, with a range of $53-95 \%$, of the households in low-income settlements reported not having helped relatives/friends/neighbours in the past one month before the survey. Money was even harder to lend as over $65 \%$ of households in both low and middle-income settlements expressed inability to lend money to anyone. Interactions with civic leaders, such as ward councilors and members of parliament, were also very low or non-existent in both low- and middleincome settlements, as over $75 \%$ of households reported not having received any assistance from civic leaders in the past twelve months before the survey. Opportunities for gaining productive skills were also very rare in both settlements, as more than $75 \%$ of households in low-income settlements reported not having been engaged in any community-based income-generating activities. The percentage of households which reported to have never received any remittances ranged from 57 to $98 \%$ in low income 
settlements. Ignorance about climate change was also expressed by over $50 \%$ of households in low-income settlements, while the score for the middle-income settlement of Kwacha East was 39\%.

Generally, the data depict communities that are very weak in organizational capacity. Social capital has been identified (Robinson et al., 2002) as the social raw material that shapes capacity to identify new information, learn and cope with change and as an important factor for long-term climate change adaptation or resilience. Emphasis should, therefore, be on strengthening social capital for skills development and establishment of vertical linkages with state structures and the private sector so as to avoid socio-economic and political marginalization within cities.

\section{Natural Hazards and Climate Variability}

The overall natural hazards and climate variability domain indices for each of the settlements (Table 3) revealed that Kawama was the least impacted by the climatic hazards examined in this study. It is evident that flooding is the most frequent climatic hazard experienced in Kitwe and is most prevalent in the slum settlements of Chipata (19\%), Ipusukilo (19\%) and Mulenga (15\%). There were no reports of flooding in Kawama.

The differential vulnerability of settlements to flooding could be attributed to the geographical positioning of the settlements within the terrain of Kitwe city. Kawama, the least vulnerable to flooding, is located at a relatively higher ground, with a mean elevation level of $1252 \mathrm{~m}$ (Table 4) and has a terrain that slopes to the north and east; providing sufficient natural drainage for storm-water. On the other hand, Chipata, Ipusukilo and Mulenga, with relatively higher vulnerability scores for flooding are actually located in the flood plain of the Kafue River.
Consequently, these settlements experience both riverine and flash flooding events.

Strong winds were also found to have had impacts on the residents of Kitwe, especially for households in Chipata, Mulenga and Ipusukilo. Climate-related injuries and deaths were rare but there were households in Ipusukilo, Mulenga and Kwacha East which were affected by them. Currently Zambia has not yet developed any effective early warning systems for severe weather events.

Overall, the patterns of vulnerability to flooding and other climate-related hazards, determined in this study, are consistent with the historical patterns in the spatial distribution of climate-related disasters that have been observed within the city of Kitwe over the years. Table 5 shows the occurrence of climate-related disasters in Kitwe for the period 1994 to 2014 and it is evident that low-income settlements, such as Chipata, Ipusukilo and others, have been subjected to flooding and subsequent loss/damage of homes. However, these events have so far not been recorded for Kawama settlement.

\section{Livelihood Vulnerability Indices}

Vulnerability is the product of intersecting social processes that result in inequalities in socioeconomic status and income, as well as in exposure (IPCC, 2014). In this context the Livelihood Vulnerability Index (LVI) served as a measure of the relative socio-economic vulnerability of the respective settlements to hazards associated with climate variability and change.

Table 4. Elevation levels of the five settlements in Kitwe

\begin{tabular}{ll}
\hline Name of Settlement & Mean elevation (m) \\
\hline Chipata & 1181 \\
Ipusukilo & 1184 \\
Mulenga & 1190 \\
Kwacha East & 1203 \\
Kawama & 1252 \\
\hline
\end{tabular}

Table 5. Occurrence of climate-related disasters in Kitwe

\begin{tabular}{ll}
\hline Year & Type of climate-related disaster \\
\hline 2014 & Over 140 houses collapsed in Ipusukilo, Twatasha and Chipata settlements of Kitwe due to protracted heavy rains. \\
2012 & 8 houses collapsed and roof of one school blown off after a hailstorm in new Ndeke township of Kitwe. \\
2011 & 64 houses in various townships in Kitwe have collapsed following torrential rains. \\
2010 & Disease outbreaks in Kitwe involving 34 cases of cholera and 387 cases of typhoid \\
2009 & 79 cases of typhoid recorded in Chamboli and Wusakile townships of Kitwe. Over 70 houses collapsed in Ipusukilo, \\
2007 & Chipata, St. Anthony and Nkadambwe compounds of Kitwe as Kafue river burst its banks following incessant rains. \\
2005 & 182 families, comprising 601 persons, left homeless after floods in Zamtan compound of Kitwe \\
2001 & Over 20 houses collapsed in Kitwe's Ipusukilo compound due to heavy rains \\
1998 & 180 houses had collapsed in Ipusukilo and 25 in Chipata townships following heavy rains. \\
1994 & Over 500 persons died of cholera in Buchi township of Kitwe.
\end{tabular}




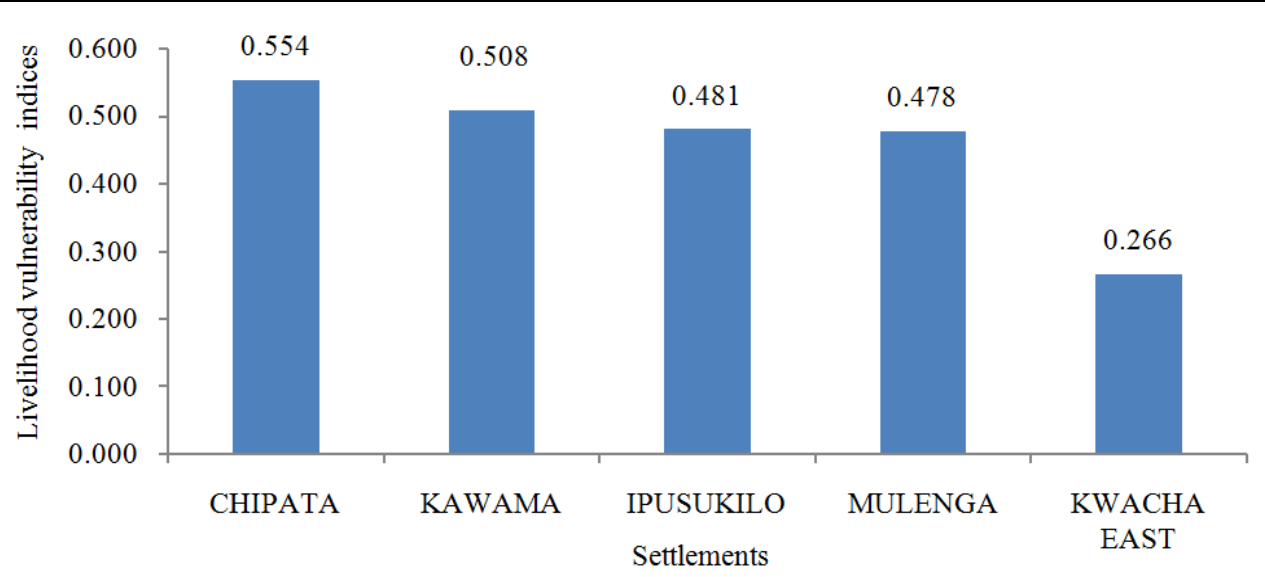

Fig. 4. Livelihood vulnerability indices of the five settlements in Kitwe

The computed LVIs of the settlements are presented in Fig. 4 and amongst the low-income settlements, the LVIs were not very different, but they were almost double that for the middle-income settlement (Kwacha east). These indices, first of all, point to the uniformity in socio-economic deprivation levels existent in lowincome settlements. Secondly, they manifest the disparities in adaptation deficits that can exist within the same city or geographical entity and hence the need for contextually and locally customized adaptation strategies. Thirdly, they point to the huge challenge facing Kitwe City Council and its residents to strengthen the climate resilience of informal settlements that constitute $70 \%$ of all households in Kitwe city.

\section{Climate Vulnerability}

Climate Vulnerability Indices (CVIs) were computed based on the IPCC definition of vulnerability (IPCC, 2007): Which is that it is directly proportional to exposure and sensitivity; and inversely proportional to adaptive capacity. The indicators used for exposure and sensitivity were the same as those used for computation of LVIs and have already been presented in Table 3 and discussed in the sections above. The section below therefore focuses on adaptive capacity whereby inverse indicators were used for the Socio-Demographic, Livelihood Strategies and Social Capital domains of livelihoods in the studied settlements.

\section{Adaptive Capacity}

The indicators used for assessing the sociodemographic component of adaptive capacity are presented in Table 6 below where it is clear that most of the households in low-income settlements, despite harbouring working age populations, have lowlyeducated heads of households. In fact the range of households with university/college education was only $1-6 \%$ in low-income settlements compared to $31 \%$ for the middle-income settlement. Tertiary education is critical for human development, creativity and technological innovation.

The computed indices for the socio-demographic domain of adaptive capacity showed Ipusukilo having the lowest score, while Kwacha East scored the highest, mainly due to its preponderance in the education indicator (Table 6).

The indicators (Table 6) for the livelihood strategies domain showed that except for Chipata, the other lowincome settlements recorded very low levels of formal employment. The number of households in formal employment for Chipata (52\%) actually exceeded that for the middle-income settlement of Kwacha East (47\%). However, comparison of Chipata with Kwacha East revealed that Chipata had very few households $(7 \%)$ who earned more than the government stipulated monthly minimum wage of about USD160.00, whereas Kwacha East recorded $33 \%$. It is also apparent that for most households in low-income areas of Kitwe, the formal employment earnings are so low as to be gobbled up by food expenses, thus making electricity and asset accumulation unaffordable for these households. The overall livelihood strategies domain index (Table 6) for Kwacha east was one to three orders of magnitude greater than the indices for low-income settlements, revealing the existence, in Kitwe, of differential socialeconomic vulnerability to current and likely future impacts of climate change.

The social capital dimensions of adaptive capacity appeared to be very low across both low and middleincome settlements in Kitwe (Table 6), considering the ubiquitous culture of kinship and extended family ties that exist in Zambia and especially in rural areas. In the critical indicators that have the potential to confer empowerment of households, such as financial exchanges, citizen-government linkages, skills development and remittances, the scores for low-income settlements were low and either equal to or better than those for the middle-income settlement. 
Table 6. Standardized indicator values of settlements for the livelihood domains of adaptive capacity

\begin{tabular}{|c|c|c|c|c|c|}
\hline \multirow[b]{2}{*}{ Indicators and respective livelihood domains } & \multicolumn{5}{|c|}{ Indicator and Domain indices of Settlements } \\
\hline & Chipata & Ipusukilo & Kawama & Mulenga & Kwacha east \\
\hline$\%$ of hhs with heads of hhs aged between $36-64$ years. & 0.560 & 0.600 & 0.460 & 0.680 & 0.700 \\
\hline$\%$ of hhs whose heads have college education. & 0.030 & 0.010 & 0.060 & 0.060 & 0.310 \\
\hline$\%$ of hhs without orphans. & 0.550 & 0.170 & 0.480 & 0.350 & 0.260 \\
\hline Socio-demographic profileindices of adaptive capacity & 0.380 & 0.260 & 0.333 & 0.363 & 0.423 \\
\hline$\%$ of hhs in formal employment. & 0.520 & 0.230 & 0.350 & 0.190 & 0.470 \\
\hline$\%$ of hhs with monthly incomes of over USD 160.00 & 0.070 & 0.040 & 0.090 & 0.020 & 0.330 \\
\hline $\begin{array}{l}\% \text { of hhs spending above USD } 10.00 / \text { month on staple } \\
\text { food (maize-meal). }\end{array}$ & 0.940 & 0.530 & 0.860 & 0.600 & 0.770 \\
\hline$\%$ of hhs spending above USD $20.00 /$ month on electricity. & 0.010 & 0.030 & 0.090 & 0.170 & 0.650 \\
\hline $\begin{array}{l}\% \text { of hhs reporting TV \& Radio assets to sell if current } \\
\text { source of income got lost }\end{array}$ & 0.240 & 0.040 & 0.200 & 0.150 & 0.510 \\
\hline Livelihood strategies indices of adaptive capacity & 0.356 & 0.174 & 0.318 & 0.226 & 0.546 \\
\hline $\begin{array}{l}\% \text { of hhs reporting having helped neighbors, friends } \\
\text { or relatives in the past one month. }\end{array}$ & 0.050 & 0.190 & 0.250 & 0.470 & 0.590 \\
\hline $\begin{array}{l}\% \text { of hhs reporting having lent money to neighbors, } \\
\text { friends or relatives in the past one month. }\end{array}$ & 0.060 & 0.140 & 0.120 & 0.340 & 0.230 \\
\hline $\begin{array}{l}\% \text { of hhs reporting having received help from civic } \\
\text { leaders in the past twelve months. }\end{array}$ & 0.010 & 0.090 & 0.020 & 0.080 & 0.020 \\
\hline $\begin{array}{l}\% \text { of hhs that have ever received community-based } \\
\text { training on income generation. }\end{array}$ & 0.020 & 0.080 & 0.060 & 0.120 & 0.120 \\
\hline$\%$ of hhs that often receive remittances. & 0.010 & 0.040 & 0.110 & 0.160 & 0.150 \\
\hline$\%$ of hhs that have ever heard about climate change. & 0.310 & 0.210 & 0.050 & 0.450 & 0.560 \\
\hline Social capital indices of adaptive capacity & 0.077 & 0.125 & 0.102 & 0.270 & 0.278 \\
\hline
\end{tabular}

NB: hhs =households

Table 7. Average values for the three domains of adaptive capacity

\begin{tabular}{ll}
\hline Adaptive capacity domains & Mean index values for all the five settlements \\
\hline Socio-demographic profile & 0.352 \\
Livelihood Strategies & 0.324 \\
Social capital & 0.171 \\
\hline
\end{tabular}

The relatively low levels of social capital within all the five settlements are exemplified in Table 7 where the average indices, over the five settlements, for the three domains/components of adaptive capacity are compared. The mean social capital index for all the five settlements was almost twice less than those for the livelihood strategies and socio-demographic profile components. Bebbington (1999) has argued that social capital brings with it an inherent capability to gain access to resources and hence to enhance the security of livelihoods and well-being. Social capital strengthening or reconstruction has, thus, to be a key element in any strategy for adapting to climatic hazards, especially for low income settlements where all the other forms of capital, such as physical, human, financial and even natural, are equally very low.

Aggregating the socio-demographic profile, livelihood strategies and social capital indices to compute the adaptive capacity indices for each settlement confirmed the relatively low adaptive capacity levels in low-income settlements compared to middle-income settlements (Fig. 6). In fact Ipusukilo recorded the lowest index of 0.17 which was 2.4 times lower than that for the middle-income settlement of Kwacha East.

These features are indicative of communities which are preoccupied with mere survival and are less able to cope with climate-related hazards. In this regard, multi-stakeholder effort is required to enhance the adaptive capacity of low-income settlements by improving the literacy, organisational ability, services, infrastructure and productive skills and income levels of citizens in these localities.

\section{Sensitivity and Exposure Indices}

The computed adaptive, sensitivity and exposure indices of the five settlements are compared in Table 8 below where it is indicative that the sensitivity score (based on indicators for Health, Food, Water, Sanitation/Drainage and Housing components) for the middle-income settlement of Kwacha East was more than twice lower than those for low income settlements. Moreover, the sensitivity indices of all the four lowincome settlements were just marginally different from one another, indicating the general inadequacy in public services, nutrition and infrastructure in these areas. 
Table 8. Adaptive capacity, sensitivity and exposure indices of the five settlements in Kitwe

\begin{tabular}{llll}
\hline Settlement & Adaptive capacity indices & Sensitivity indices & Exposure indices \\
\hline CHIPATA & 0.241 & 0.551 & 0.396 \\
IPUSUKILO & 0.171 & 0.444 & 0.395 \\
KAWAMA & 0.229 & 0.478 & 0.362 \\
MULENGA & 0.274 & 0.456 & 0.397 \\
KWACHA EAST & 0.405 & 0.194 & 0.372 \\
\hline
\end{tabular}

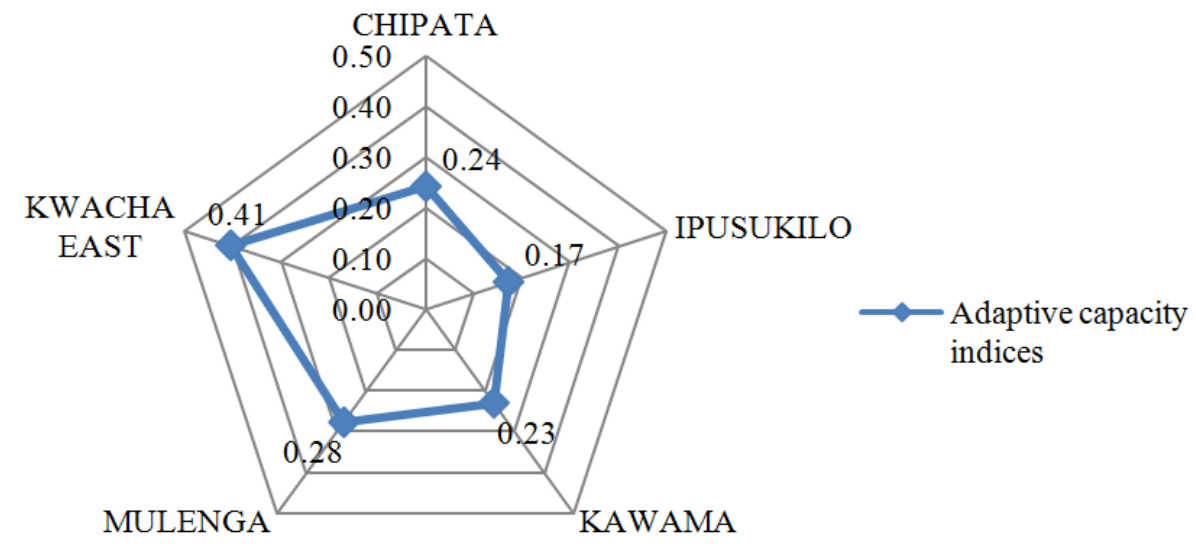

Fig. 6. Adaptive capacity indices of the five settlements in Kitwe

The exposure indices were computed based on the indicators for the Natural Disaster and Climate Variability component. The exposure indices for the five settlements confirm the empirical fact that exposure is mainly a function of the geographical position and terrain of the locality and is independent of the statutory and/or socio-economic status of the locality.

The adaptive capacity index for the middle-income settlement (Kwacha East) was greater than the sensitivity index. However, for all the low-income settlements, the sensitivity indices were greater than the adaptive capacity indices.

According to the IPCC (2012), there is high confidence that, the intensity of extreme climate and weather events-low-probability, high-intensity - and exposure to them tend to be more pervasive in explaining disaster loss than vulnerability itself. But as the events get less extreme-higher-probability, lower-intensity - the vulnerability of exposed elements plays an increasingly important role in explaining the level of impact. Therefore, in the context of this study, the middle-income settlements (high adaptive capacity but low sensitivity indices) of Kitwe would be expected to suffer losses and damages under extreme climate events, whereas, lowincome settlements could experience adverse effects even under ordinary variability in climatic conditions due to their high sensitivity to climate hazards.

\section{Climate Vulnerability Indices}

The Climate Vulnerability Indices (CVIs) of the five settlements are presented in Fig. 7 below, where the low- income settlements of Ipusukilo and Chipata recorded very high $(>0.8)$ vulnerability scores. This can be explained by low education levels in Ipusukilo, with over $60 \%$ of residents in informal employment and lacking any assets and savings to cushion their livelihoods during times of socio-economic shocks. Moreover, almost $50 \%$ of the households resorted to one meal per day during the food-deficit times of the rainy season. In the case of Chipata, the settlement had no dedicated health centre, used pit latrines for sanitation, sourced domestic water from shallow wells and experienced outbreaks of diarrheal diseases. Drainages were unavailable, while housing structures were of substandard materials. Linkages with civic leaders were absent and skills development schemes in the community did not exist.

The severity of climate vulnerability of Kawama and Mulenga (Fig. 7) could be classified as high (0.6-0.8). Kawama was vulnerable with respect to its dependence on shallow wells for potable water and occurrence of water-related communal conflicts. With over $50 \%$ of the households with only primary education, access to adequate incomes has been constrained by lack of adequate job opportunities and insufficient or inappropriate income-generating skills.

Mulenga was vulnerable with respect to its relatively heightened incidences of respiratory diseases. The situation was further compounded by excessive informal employment levels of over $70 \%$, resulting in relatively low mean monthly income levels of about 50 USD for the majority of the residents. 


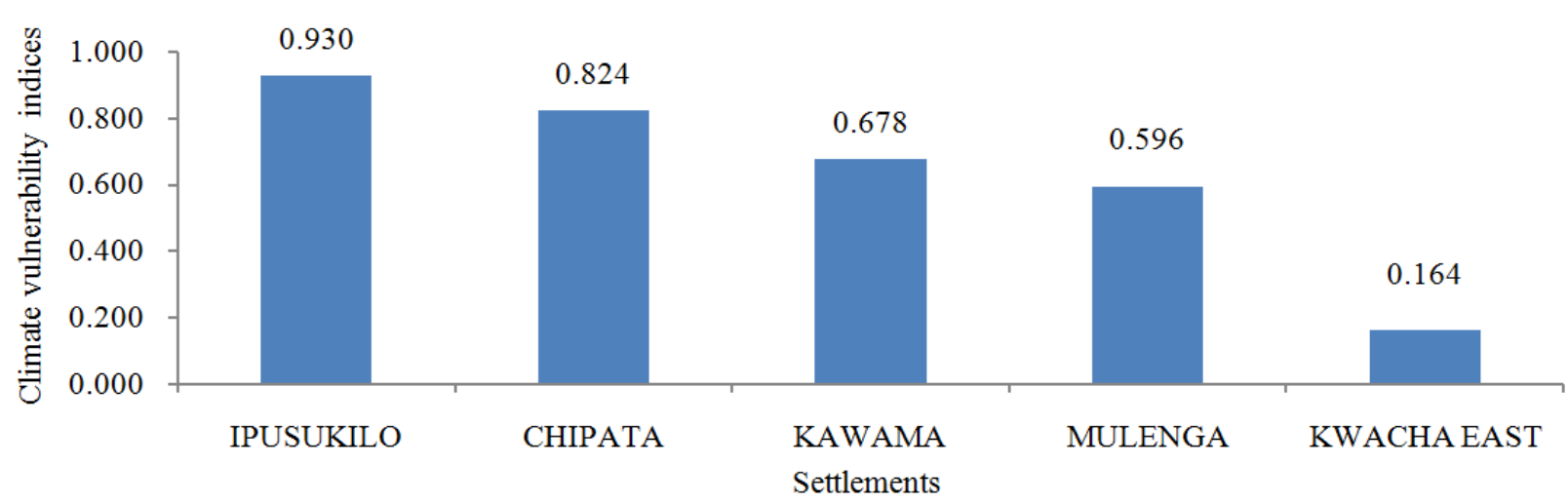

Fig. 7. Climate Vulnerability Indices (CVIs) of the five settlements in Kitwe

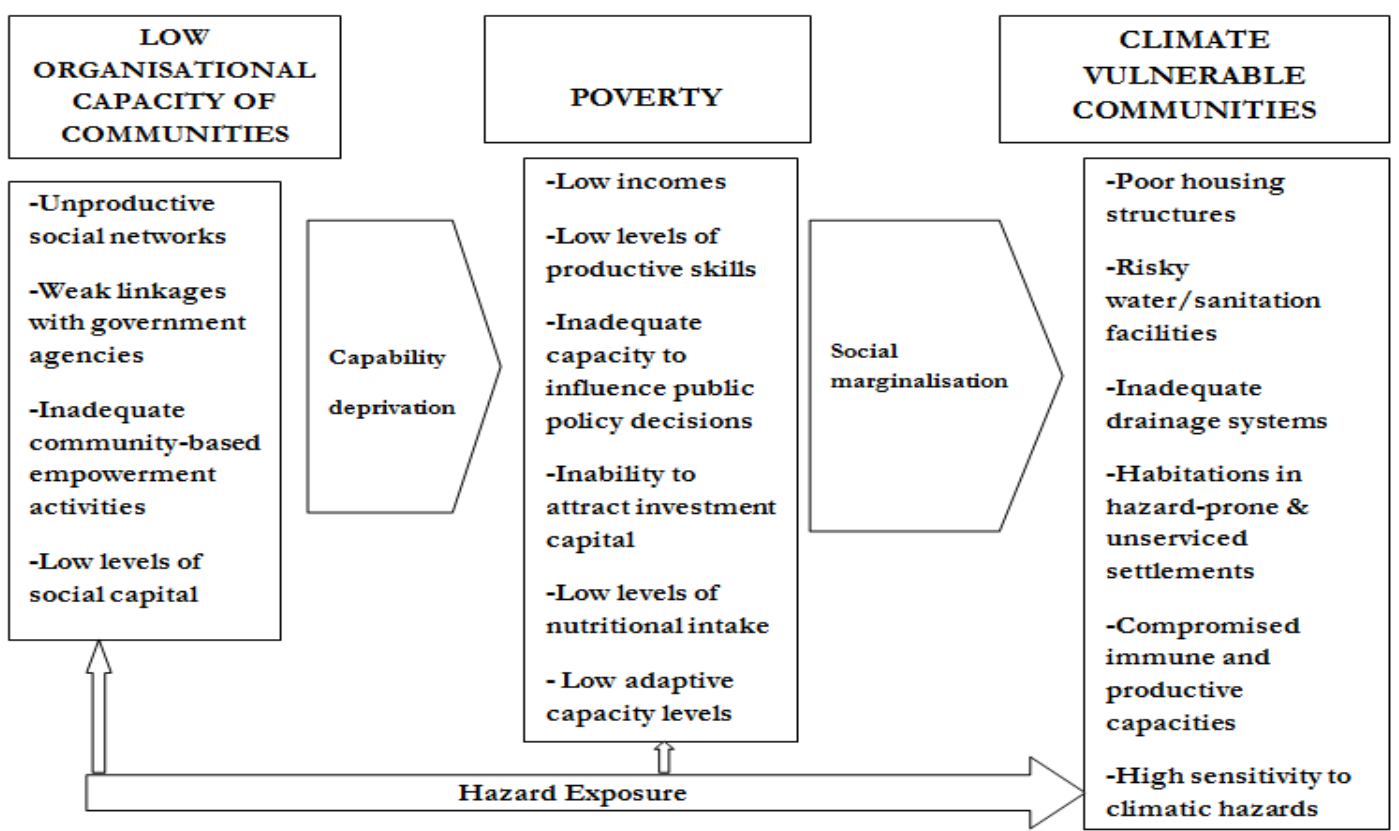

Fig. 8. An empirical model of organizational capacity, poverty and climate vulnerability linkages (Source: Own elaboration)

The middle-income settlement of Kwacha East recorded relatively low levels of climate vulnerability. However, issues of food insecurity, low incomes, orphans and low levels of social capital were existent as well. Overall, the CVI for Kwacha east was almost five times lower than the average CVI for all the four informal settlements (Fig. 7). Therefore, the lesson here is that regularizing and upgrading of slums is already a first and critical step for municipalities towards building climate and livelihood resilience in these communities.

\section{Conceptualisation of Role of Social Capital in Climate Resilience}

The empirical findings of this study have clearly demonstrated that ranking of the critical determinants of adaptive capacity, such as literacy levels and productivity of livelihood strategies, social capital had the least score for the settlements covered in this study. Overall, the results of this study point to the existence of a relationship between social capital and vulnerability of settlements to climate variability/change.

The relationships can be conceptualized into a framework or schematic model as presented in Fig. 8. It is hypothesized that climate vulnerability in low-income settlements is mediated via poverty and its determinants. In the case of urban settlements, poverty is linked to the inability of households to access adequate capabilities that can enable them to operate competitively and effectively in a cash-driven economy.

The fundamental assertion here is that the main barrier to poverty-reduction in Africa and Zambia is the low level of organizational capacity to mobilize both 
internal and external resources for endogenous capacitybuilding and wealth creation. This is depicted in the derived conceptual framework in Fig. 8, where poor organizational capacity translates into capability deprivation or diminished community capacity to mobilize sufficient resources or assets for wealth creation. The consequence of deprivations in sociallyappropriate or economically-compatible capabilities is poverty, which leads to social and economic marginalization. More importantly, marginalization limits peoples' access to food, productive resources and capital. The overall outcome of these multiple deprivations are high sensitivity and low adaptive capacity which are liable to be exacerbated by exposure to hazards associated with severe weather caused by increased variability of climate and/or anthropogenic climate change. However, in certain cases, exposure to climate disasters may actually strengthen the organizational capacity of communities. How and under what conditions this happens have yet to be investigated.

The implication of the conceptual framework (Fig. 8) for practice or interventions is that communities need to or must be assisted by government and/or municipalities to organize and govern themselves into groupings which can mobilize labour, skills and technology and financial resources for wealth creation. In the context of Zambia each Ward Councilor should mobilize residents (labour) in his ward to form economic production cooperatives with the assistance of universities (skills and technology) and members of parliament (financial resources from the constituency development fund). The main activities of these cooperatives/enterprises should be manufacturing for value addition to the numerous natural and agricultural raw materials that are abundantly available in all parts of the country. The output commodities and services of these cooperatives must be demand-driven and competitive in urban markets to attract the participation of the private sector and banks. In principle and practice, poor people have the capacity to exit poverty and given the opportunity-the right policies and an appropriate enabling environment - they will do so and improve their standards of living, as well as resilience to adverse impacts of climate variability/change.

\section{Conclusion}

This empirical study of climate vulnerability at household level in urban Kitwe has demonstrated that informal settlements lack climate risk-reducing infrastructure and resilient livelihoods. They are characterized by makeshift housing structures, low literacy levels, high levels of insecure informal employment with concomitant low incomes, inadequate access to water and sanitation services, lack of storm drainages, depressing levels of nutritional and health status and tendency to be located in hazard-prone areas. These are the offshoots of poverty. On the other hand, poverty thrives in societies with poor organisational capacities, whereby governance systems fail to mobilise local intellectual capacities for purposes of transforming their natural resource endowments into broader economic development and long-term prosperity for their people. It is thus incumbent upon Kitwe City Council (KCC) and other councils in Zambia and the world with similar conditions to implement the following:

- Upgrading of informal settlements through provision of piped water, sewerage services, roads and drainages, electricity, including garbage collection

- Introduction of climate-resilient building codes so as to minimize and/or prevent the damage and loss of housing infrastructure and possibly lives. The only caution is that these new codes should not act as barrier, cost-wise, to home ownership for lowincome residents

- Promoting skills development for povertyreduction and entrepreneurship for purposes of formal job creation, increasing disposable incomes and diversifying livelihood opportunities. More importantly for $\mathrm{KCC}$ is the fact that the majority of Kitwe residents do not contribute to its revenue base through direct taxes and consequently $\mathrm{KCC}$ is perennially running budget deficits. It is also self-evident that upgrading of slums with capital-intensive basic services infrastructure for climate-vulnerability reduction becomes financially intractable and unsustainable in the face of such massive poverty. It is, thus, imperative for government (s) to complement private-sector efforts and accelerate the pace of poverty reduction

- Improving food security for low-income urban residents who have been forced into agriculture by joblessness, despite having little or no practical experience and skills required for farming. These residents can be mobilised into cooperatives and trained in sustainable and climate-resilient agricultural practices. The productivity of these cooperatives should target yields which ensure allyear round food access for the involved households and a surplus for marketing

- Developing strategies for monitoring and minimizing the public health impacts of climate variability/extremes through research, adequate preventive measures, preparedness, timely response and effective management of disease outbreaks 
- Developing a climate-resilience action plan for the entire city so as to spur poverty alleviation and inclusive sustainable climate-resilient development

Based on the empirical outputs of this study, a conceptual framework has been developed that has shown that organisational social capital is the cornerstone of wealth creation and development of socio-economic competitive advantage for any society or nation. Even though further research is required to establish the contextual relationship between social capital and environmental/socio-economic shocks, it is postulated that poor organisational capacity among the residents of Kitwe and Zambia as a whole constitute the key barriers to poverty reduction and climate resilience. How else could people be economically poor in a country like Zambia that is endowed with a multiplicity of natural resources? In this regard, Zambia's current policy of job creation is solely dependent on Foreign Direct Investment (FDI). However, in the face of globalisation where Zambia has to compete with the rest of the world, the inflow rates of FDI have failed to match the local demand for jobs. It is thus argued that the government of Zambia should develop policies that enable the transformation of universities and R and D institutions from mere producers of graduates and scientific knowledge to those capable of creating tangible industrial goods and services and thus serve as platforms for the emergence of the manufacturing sector in Zambia.

Almost all the products and processes of wealth creation are climate-sensitive. It thus becomes an economic imperative for all wealth creation interventions to integrate the triple objectives of climate compatible development, which include income generation, reduction of greenhouse gas emissions and improving the climate resilience of communities. This study and its methodological approach are straight forward enough to be replicated in other towns of Zambia and the world and in fact serve to provide a baseline for monitoring progress and evaluation of impacts of future development and climate change adaptation interventions, including progress made on achievements of the UN sustainable development goals.

\section{Acknowledgement}

This research was supported by a grant from the International Institute for Environment and Development (IIED), UK and in-kind contributions from the Copperbelt University, Zambia; Kitwe City Council, Zambia and People's Process on Housing and Poverty in Zambia.

\section{Author's Contributions}

George Kasali, Julius Kanyembo, Mapenzi Phiri and Mainza Sibajene contributed equally in design of questionnaire,

data collection, data analysis/interpretation, writing and publication of the manuscript.

\section{Ethics}

Authors declare no conflict of interest.

\section{References}

Barnett, G., R.M. Beaty, D. Chen, S. McFallan and J. Meyers et al., 2013. Pathways to climate adapted and healthy low income housing. National Climate Adaptation Research Facility, Gold Coast.

Bebbington, A., 1999. Capitals and capabilities: A framework for analyzing peasant viability, rural livelihoods and poverty. World Dev., 27: 2021-44. DOI: 10.1016/S0305-750X(99)00104-7

CSO, 2011. Zambia 2010 census of population and housing. Central Statistical Office, Lusaka

FAO, 2008. The State of Food Insecurity in the World 2008, High food prices and food security-threats and opportunities. Food and Agriculture Organization of the United Nations, Rome, Italy.

Ferris, E., 2011. Protecting civilians in disasters and conflicts. Brookings Policy Brief 182, Brookings Institute, Washington, DC.

Hahn, M.B., A.M. Riederer and S.O. Foster, 2009. The livelihood vulnerability index: A pragmatic approach to assessing risks from climate variability and change-A case study in Mozambique. Global Environ. Change, 19: 74-88.

DOI: 10.1016/j.gloenvcha.2008.11.002

Harlan, S.L., A.J. Brazel, L. Prashad, W.L. Stefanov and L. Larsen, 2006. Neighborhood microclimates and vulnerability to heat stress. Soc. Sci. Med., 63: 2847-2863.

DOI: $10.1016 /$ j.socscimed.2006.07.030

Hayumbu, P., 2005. Respiratory diseases among Zambian copper miners: Silicosis and tuberculosis incidence trends during the period 1995-2003. Occupational and Environmental Epidemiology MPH Research Paper, (EHS 697), University of Michigan, Ann Arbor.

IPCC, 2007. Climate change 2007: Synthesis Report. Contribution of Working Groups I, II and III to the Fourth Assessment Report of the Intergovernmental Panel on Climate Change, IPCC, Geneva, Switzerland.

IPCC, 2012. Managing the risks of extreme events and disasters to advance climate change adaptation. A Special Report of Working Groups I and II of the Intergovernmental Panel on Climate Change, Cambridge University Press, Cambridge, UK and New York, USA. 
IPCC, 2013. Technical Summary. In: Climate change 2013: The Physical Science Basis. Contribution of Working Group I to the Fifth Assessment Report of the Intergovernmental Panel on Climate Change. Cambridge University Press, Cambridge, United Kingdom and New York, USA.

IPCC, 2014. Summary for policymakers. In: Climate Change 2014: Impacts, Adaptation and Vulnerability, Part A: Global and Sectoral Aspects. Contribution of Working Group II to the Fifth Assessment Report of the Intergovernmental Panel on Climate Change. Cambridge University Press, Cambridge, United Kingdom and New York, USA, pp: 1-32.

JCTR, 2016. JCTR basic needs basket. October Issue; Jesuit Centre for Theological Reflection, Lusaka.

Kamuliwo, M., C. Emmanuel, H. Ubydul, M. Mercy and S. Chadwick et al., 2013. The changing burden of malaria and association with vector control interventions in Zambia using district-level surveillance data, 2006-2011. Malaria J., 12: 437-437. DOI: $10.1186 / 1475-2875-12-437$

KCC, 2012. The 2012-2016 Kitwe city council strategic plan. Kitwe City Council, Kitwe.

Malama, A. and S. Sharples, 1997. Thermal performance of traditional and contemporary housing in the cool season of Zambia. Build. Environ., 32: 69-78. DOI: 10.1016/S0360-1323(96)00036-4

Mearns, R. and A. Norton, 2009. Social dimensions of climate change: Equity and vulnerability in a warming world. World Bank, Washington.

MFNP, 2011. Zambia strategic programme for climate resilience. Ministry of Finance and National Planning, Lusaka.

MTENR, 2010. National climate change response strategy. Ministry of Tourism, Environment and Natural Resources, Lusaka.

Pelling, M., 2003. The Vulnerability of Cities: Natural Disasters and Social Resilience. 1st Edn., Earthscan Publications, London, ISBN-10; 1853838292, pp: 212.

Ribot, J.C., 2009. Vulnerability does not Just Fall from the Sky: Toward Multi-Scale Pro-poor Climate Policy. In: Social Dimensions of Climate Change: Equity and Vulnerability in a Warming World, Mearns, R. and A. Norton (Eds.), The World Bank, Washington, DC.

Robinson, L.J., A. Schmid and M.E. Siles, 2002. Is social capital really capital? Rev. Soc. Economy, 60: 1-21. DOI: 10.1080/00346760110127074

Sharma, N., F.A. Johnson, C.W. Hutton and M. Clark, 2010. Hazard, vulnerability and risk on the brahmaputra basin: A case study of river bank erosion. Open Hydrol. J., 4: 211-226.

DOI: $10.2174 / 1874378101004010211$
Tacoli, C., H.X. Owusu, M. Owusu, L. Kigen and J. Padgham, 2013. The role of local government in urban food security. IIED Policy Briefing, September issue, IIED, London.

Turner, D.W., 2003. Bananas-response to temperature. Agfact H6.2.6; Division of Agricultural Services; New South Wales Department of Agriculture; Alstonville.

UN HABITAT, 2009. Zambia: Kitwe urban profile. United Nations Human Settlements Programme, UNHABITAT Regional and Information Offices, Nairobi.

UNISDR, 2011. Global assessment report on disaster risk reduction: Revealing risk, redefining development. United Nations International Strategy for Disaster Reduction, Geneva, Switzerland.

Vaneckova, P., P.J. Beggs and C.R. Jacobson, 2010. Spatial analysis of heat-related mortality among the elderly between 1993 and 2004 in Sydney, Australia. Soc. Sci. Med., 70: 293-304. DOI: $10.1016 /$ j.socscimed.2009.09.058

WHO, 2005. Immunization coverage cluster surveyreference manual. World Health Organisation Document Production Services, Geneva, Switzerland.

WHO, 2007. The world health report 2007: A safer futureglobal public health security in the 21 st century. World Health Organization, Geneva, Switzerland.

World Bank, 2013. Zambia economic brief-Zambia's jobs challenge-realities on the ground. World Bank, Washington.

ZMD, 2016. Zambia evening weather forecast, Monday (10/10/16), Ministry of Transport and Communications, Livingstone.

ZMD, 2015. Zambia evening weather forecast, Monday (18/06/15), Ministry of Transport and Communications, Livingstone.

ZVAC, 2008. Southern province rapid flood impact assessment report. Zambia Vulnerability Assessment Committee, Disaster Management and Mitigation Unit, Office of the Vice-President, Lusaka. 